\title{
THE ESTIMATION OF NORADRENALINE IN URINE AND ITS EXCRETION IN NORMAL AND HYPERTENSIVE SUBJECTS
}

\author{
BY \\ W. J. GRIFFITHS AND SUSANNE COLLINSON \\ From the Department of Chemical Pathology, St. Thomas's Hospital, London
}

(RECEIVED FOR PUBLICATION SEPTEMBER 7, 1956)

Recognition of the association of paroxysmal hypertension with phaeochromocytomata, actively secreting tumours of the chromaffin tissue of the adrenal medulla, has resulted in the need for more careful scrutiny of hypertensive patients for evidence of this disease which, if found, may be cured by surgical removal of the growth.

Much help in diagnosis may be obtained by the trial of provocative agents such as histamine, or of blocking, adrenolytic drugs like " rogitine," but false results are not uncommon and the diagnosis may be left in doubt.

Following the demonstration by Holton (1949) that noradrenaline is present in the adrenal medullary tumours, Engel and von Euler (1950) reported that the excretion of the catecholamines adrenaline and noradrenaline in the urine is markedly increased in the presence of a phaeochromocytoma and this is now the most reliable diagnostic method. Unfortunately, the complexity of the methods for determining these substances in the urine has put them beyond the capacity of most clinical laboratories, and it was with the object of evolving a relatively simple clinical method that this work was undertaken.

Two methods for the determination of catecholamines are available: bio-assay, which is satisfactory but involves the use of an animal preparation as a test-object for the pressor activity of urine extracts, and the fluorimetric, for which a fluorimeter of sufficient sensitivity has not, until recently, been commercially available in this country.

Fluorimetric methods for the determination of catecholamines in blood have been described by Lund (1949), Weil-Malherbe and Bone (1952, $1953,1954)$ and in urine by Goldenberg, Serlin, Edwards, and Rapport (1954) and von Euler and Floding (1955a, 1955b). Weil-Malherbe and Bone constructed their own fluorimeter, and a similar apparatus was used by von Euler and Floding; Lund employed a Coleman 12B fluorimeter, which in a modified form was also used by Goldenberg et al.

\section{Method}

Separate determination of adrenaline and noradrenaline increases the time and labour involved, and since it is not essential for diagnostic purposes it will not be described in this paper; methods are described by Lund (1950), Goldenberg et al. (1954), and von Euler and Floding (1955a).

The principle of the method is as follows. The acidified urine is heated to hydrolyse the conjugated catecholamines, which are then adsorbed on aluminium $\overline{\overrightarrow{0}}$ hydroxide and eluted with a mixture of acetone and 3 ethanol (von Euler and Hellner, 1951; Goldenberg et al., 1954). A sample of the eluate, after concentration, is subjected to paper chromatography with $n$-butanol-acetic acid-water (Shepherd and West, 1953) and the separated catecholamines eluted with dilute $\dot{0}$ $\mathrm{HCl}$. Fluorimetric analysis is performed at $p \mathrm{H} 6$ by the method of von Euler and Floding (1955a).

We have measured the fluorescence with a Hilger

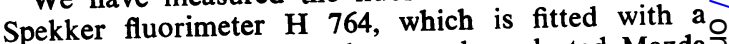
125-watt mercury vapour lamp and a selected Mazda type 27 M 3 visible photo-multiplier. A Cambridge spot galvanometer was used with a low-powered lens in front of the scale to increase the precision of adjust-N ment to the null-point.

With adrenaline and noradrenaline greatest sensi $\tilde{O}$ tivity is obtained by the use of Chance $O B 10$ glass $(440 \mathrm{~m} \mu)$ as a primary filter, but we found, in agree $\sigma$ ment with Lund (1949), that with this filter the blank values of the urine extracts are unduly large. W\& have, therefore, used Hilger 556 filters (Wood's glass $365 \mathrm{~m} \mu$ ) throughout this work. On the left-hand, com pensating side of the instrument one neutral filter (Hilger 508) was also necessary. Chance OY 4 glass? which cuts off light below $510 \mathrm{~m} \mu$, served as a secone dary filter. Calorex heat-resisting filters were place $\$$ on each side of the light source. All filters were $2 \mathrm{~mm}$ thick. The "coarse" sensitivity of the power unit had to be set at 9 . 
Calibration Graph for Noradrenaline.-Standard solutions were prepared from L-noradrenaline bitartrate and estimated by the method of von Euler and Floding (1955a). Oxidation with the ferricyanide was allowed to proceed for three minutes, and 15 minutes after addition of the sodium hydroxide reagent readings were made against a solution of quinine sulphate containing $0.075 \mu \mathrm{g}$. per $\mathrm{ml}$. The transmission scale of the fluorimeter was used (\% tr.).

The quinine sulphate was made by diluting $0.75 \mathrm{ml}$. of a stock solution containing $20 \mathrm{mg}$. quinine sulphate dissolved in $1,000 \mathrm{ml}$. N/10 sulphuric acid to $200 \mathrm{ml}$. with $\mathrm{N} / 10$ sulphuric acid. These solutions are stable.

The reagent-blank values ranged from 10 to $12 \%$ tr. Sodium hydroxide without ascorbic acid was used in the blanks for these standard values as for the assay of urine extracts. If the ascorbic acid-sodium hydroxide reagent is used the values obtained are about $2 \%$ tr. higher ; it is for this reason that the graph does not pass through the origin (Fig. 1).

Adrenaline.- Under the same conditions we have found that, weight for weight, $\%$ tr. values for

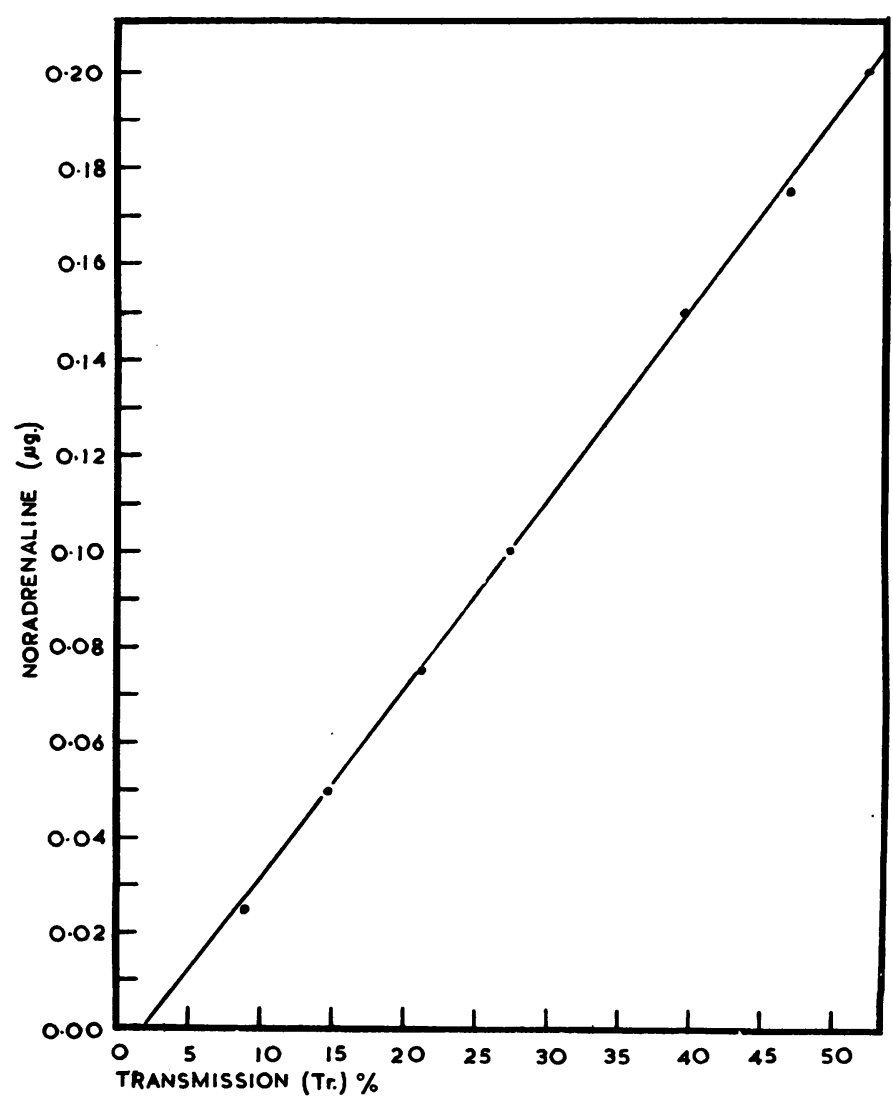

FIG. 1.-Each point is the mean of six determinations. The coefficients of variation (\%) of the fluorimeter readings (tr.\%) in ascending order from $0.025 \mu \mathrm{g}$. were: $4.3,4.2,4.7,2.2,4.3,5.3$, and 2.6 . adrenaline at $\mathrm{pH} 6$ are approximately $30 \%$ higher than those given by noradrenaline.

Extraction of Catecholamines from Urine.-The patients should not be given medicines or vitamins during the period of urine collection, since these might give high blank values on estimation.

Twenty-four-hour specimens of urine are collected in bottles containing $10 \mathrm{ml}$. concentrated hydrochloric acid and kept in a cool place. The volume of the specimen is noted, and if less than $1,500 \mathrm{ml}$. it is made up to this figure with water.

The urine is filtered and $500 \mathrm{ml}$. measured into a litre flask. The reaction is adjusted to $p \mathrm{H} 1.5-2.0$ with concentrated hydrochloric acid, using short range test-paper and the flask immersed in boiling water for 30 minutes. The flask is shaken occasionally and the reaction readjusted, if necessary, with hydrochloric acid. The contents of the flask are then cooled under running water.

The urine is transferred to a litre beaker and $8 \mathrm{ml}$. of $20 \%$ aluminium sulphate (A.R.) is added. Whilc the fluid is vigorously agitated by a magnetic stirrer $3 \mathrm{~N}$ sodium hydroxide is added drop-wise at a rate of about 60 drops per minute until the $p \mathrm{H}$, continuously determined with a glass electrode, reaches 7.7. In most cases a precipitate of aluminium hydroxide begins to form at about $p \mathrm{H} 4$ and becomes dense as the end-point is reached. With some specimens of urine, however, little or no precipitate forms

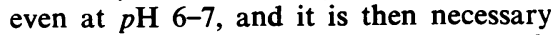
to add a further $8 \mathrm{ml}$. of aluminium sulphate and continue the addition of sodium hydroxide to $p \mathrm{H} \mathrm{7.7.} \mathrm{Rarely,} \mathrm{a} \mathrm{third}$ addition of aluminium sulphate may be necessary to produce a satisfactory precipitate as evidenced by dense cloudiness of the liquid.

After stirring for one minute at $p \mathrm{H} 7.7$ the precipitate is immediately collected by centrifuging at 1,800 r.p.m. for 10 minutes in two $250 \mathrm{ml}$. bottles. A deposit having a total volume of $10-20 \mathrm{ml}$. is satisfactory. Without delay the precipitate is dissolved by adding $1 \mathrm{ml}$. of $6 \mathrm{~N}$ sulphuric acid to each bottle, closing with a stopper and shaking vigorously for a few seconds. If the mixture does not become clear a few more drops of sulphuric acid are added. The brown solution is transferred quantitatively with a small quantity of water to a $100 \mathrm{ml}$. conical flask and the reaction brought to $p H$ 3.0 (glass electrode) by the addition of $3 \mathrm{~N}$ sodium hydroxide. Great care is necessary during this procedure to avoid local high alkali concentration. The alkali is added drop-wise from a fine pipette during brisk agitation of the flask, especially after each drop of alkali. 
When the $p H$ reaches about 3.0 and re-precipitation of the aluminium hydroxide has begun, neutralization is continued with $\mathrm{N}$ sodium hydroxide to $p \mathrm{H} 3.7$.

The volume of the creamy mixture is roughly measured and it is transferred with four volumes of ethanol acetone $(1: 1)$ to a $250 \mathrm{ml}$. flask, shaken, and placed in a refrigerator $\left(4^{\circ} \mathrm{C}\right.$.) overnight.

Paper Chromatography.-Two $1 \mathrm{ml}$. samples of the eluate are subjected to paper chromatography. The ethanol-acetone mixture is shaken and its volume measured; the volume occupied by the precipitate is ignored. A portion is centrifuged and $1 \mathrm{ml}$. of the clear supernatant fluid is measured into a $15 \mathrm{ml}$. conical centrifuge tube. One drop of $5 \%$ acetic acid is added. The tube is placed in a rack in a sloping, almost horizontal position and the fluid concentrated by directing a stream of compressed nitrogen on to the surface from a capillary tube at room temperature. The acetone and ethanol are quickly removed, and after about 10 minutes there remains a small residue of about $0.3 \mathrm{ml}$.

In the subsequent chromatography a marker is needed to locate the position of the noradrenaline. A further quantity of $1 \mathrm{ml}$. of the eluate in another tube. to which is added about $5 \mu \mathrm{g}$. of noradrenaline $(0.05$ $\mathrm{ml}$. of $0.01 \%$ noradrenaline in $5 \%$ acetic acid), is concentrated as described above. If a number of different eluates is being run on one paper a sample of any one will serve as a marker.

The catecholamines are separated by ascending, onedimensional, chromatography. We have found Whatman No. 41 paper (for chromatography), which is $\mathrm{HCl}$ - and HF-washed, to give the best results. We use 12 in. by 12 in. sheets which, after folding concertina-wise, are cut to form seven connected strips or lanes some $24 \mathrm{~cm}$. long and $3 \mathrm{~cm}$. wide. The size of the paper and the number of lanes will depend on the number of specimens and the apparatus available ; a movement of the solvent front of about $25 \mathrm{~cm}$. is desirable.

A pencil line is drawn parallel about $3.5 \mathrm{~cm}$. from one edge to traverse the lanes at about $1 \mathrm{~cm}$. from their origins. Using a capillary pipette and teat the concentrated eluates are applied along the pencil lines by repeated applications, drying with a fan at room temperature. The fluid should not be allowed to spread more than about $0.5 \mathrm{~cm}$. on each side of the line. Finally, the tubes are rinsed twice with two drops of water and the washings transferred to the paper.

The paper is suspended with the lower end in the solvent prepared as described by Goldenberg et al. (1954) : 4 parts of $n$-butanol, 1 part of glacial acetic acid (A.R.), and 5 parts of distilled water are shaken vigorously in a separating funnel; after separation the upper layer is transferred to a centrifuge tube and placed in the refrigerator for about 30 minutes; the mixture is then centrifuged and the clear fluid poured into the trough of the tank. The lower, aqueous, phase is transferred to a beaker and placed in the tank. The paper is developed at room temperature until the solvent reaches the top, conveniently overnight.

The operations described should be carried out in diffused light and the chromatography tank covered with a cloth or kept in the dark.

Elution of Catecholamines.-The sheet is removed from the tank and dried for one hour in a current of air at room temperature and in diffused light. The lane containing the marker is sprayed with solution containing $0.44 \%$ potassium ferricyanide in $0.2 \mathrm{M}$ phosphate buffer $p \mathrm{H} 8.3$, adjacent lanes being carefully shielded. The position of the noradrenaline will be indicated by a pink band some $6 \mathrm{~cm}$. from the line of application.

Using a ruler parallel pencil lines are drawn across the paper lanes about $1.5 \mathrm{~cm}$. on each side of the noradrenaline band. The paper enclosed between the pencil lines is cut out, folded concertina-wise some seven times and dropped into $15 \mathrm{ml}$. stoppered tubes containing $10 \mathrm{ml}$. N/1,000 hydrochloric acid. The tubes are placed in a shaker in a horizontal position, protected from light, and gently rocked about 60 times a minute for one hour.

Estimation of Catecholamines,-After elution and without delay two $4 \mathrm{ml}$. samples, one of which serves as a blank, are delivered into cylinders graduated at $10 \mathrm{ml}$. and containing $1 \mathrm{ml}$. of acetate buffer $p \mathrm{H} 6.0$. After making the volume up to $8 \mathrm{ml}$. with water the estimation is carried out at $\mathrm{pH} 6$ as described by von Euler and Floding (1955a).

If the readings are within the range of the standard graph the duplicate eluate is assayed in a similar manner ; if the amount of catecholamines is too high a smaller amount of eluate $(2$ or $1 \mathrm{ml}$.) is taken for estimation:

Calculation :

$$
\begin{aligned}
& \text { noradrenaline } \times \frac{\text { vol. eluate }}{\text { vol. applied to }} \times \frac{10}{\text { vol. eluate of }} \\
& \text { paper } \\
& \text { paper taken } \\
& =\mu \mathrm{g} \text {. per } 500 \mathrm{ml} \text {. urine. }
\end{aligned}
$$

The mean value of the duplicate estimations is used for calculation.

Accuracy of Method.-In order to test the accuracy of the method 11 duplicate $500 \mathrm{ml}$. samples of urine were assayed. The total catecholamines present, expressed as noradrenaline, ranged from $15 \mu \mathrm{g}$. to $40 \mu \mathrm{g}$., mean $26 \mu \mathrm{g}$. ; the S.D. for a single determination was $\pm 1.9 \mu \mathrm{g}$.

Recovery for Noradrenaline from Urine.-Duplicate urine samples of $500 \mathrm{ml}$., to one of which noradrenaline was added in amounts of 10 to $1,000 " \mathrm{~g}$., were assayed. The results, shown in Table $I$, show that recoveries ranged from $79 \%$ to $109 \%$, with a mean value of $92 \%$. 
TABLE I

RECOVERY OF NORADRENALINE FROM $500 \mathrm{ML}$. URINE

\begin{tabular}{c|c}
\hline $\begin{array}{c}\text { Noradrenaline } \\
\text { Added }(\mu \mathrm{g} .)\end{array}$ & $\begin{array}{c}\text { Recovery } \\
(\%)\end{array}$ \\
\hline 10 & 100 \\
10 & 109 \\
20 & 85 \\
50 & 95 \\
50 & 90 \\
50 & 93 \\
100 & 102 \\
100 & 80 \\
100 & 80 \\
150 & 98 \\
150 & 94 \\
150 & 100 \\
250 & 99 \\
250 & 81 \\
250 & 80 \\
500 & 96 \\
500 & 85 \\
500 & 79 \\
1,000 & 100 \\
\hline
\end{tabular}

\section{Comparison of Biological and Fluorimetric Methods}

The pressor activity of a number of samples of urine was determined on the cat preparation. The animals were anaesthetized with chloralose and $2 \mathrm{mg}$. per $\mathrm{kg}$. of atropine was injected intravenously followed by $0.1 \mathrm{mg}$. per $\mathrm{kg}$. of ergotoxine intramuscularly.

Ethanol-acetone eluates, which had been fluorimetrically assayed, were evaporated in vacuo as described by Goldenberg et al. (1954) and the residues taken up in $0.01 \mathrm{~N}$ hydrochloric acid. After suitable dilution they were injected into the femoral vein of the cat preparation and the effects compared with those produced by known amounts of L-noradrenaline. The results are given in Table II. The difference between the two series of results is not significant $(P=0.7)$.

TABLE II

COMPARISON OF BIO-ASSAY AND FLUORIMETRY $(\mu \mathrm{G}$ NORADRENALINE PER 500 ML. URINE)

\begin{tabular}{c|c|c}
\hline Specimen No. & Bio-assay & Fluorimetry \\
\hline 1 & 25 & 31 \\
2 & 40 & 45 \\
3 & 20 & 18 \\
4 & 18 & 31 \\
5 & 20 & 25 \\
6 & 15 & 29 \\
7 & 22 & 24 \\
8 & 30 & 30 \\
9 & 20 & 22 \\
10 & 20 & 24 \\
11 & 15 & 24 \\
12 & 20 & 60 \\
13 & 40 & 200 \\
14 & 190 & 42 \\
\hline
\end{tabular}

The figures are no more than an approximation because the adrenaline present would, as compared with noradrenaline, exercise a smaller pressor effect on the cat and yield a higher fluorimetric reading. Since, however, the adrenaline content of the urine of the patients represented in Table II would be expected to be small the results are probably not appreciably distorted.

\section{The Catecholamine Excretion of Normal and Hypertensive Subjects}

The urinary output of total catechols as noradrenaline was determined in normal subjects and hypertensives (Table III). The mean value for the normals was $89 \mu \mathrm{g}$. per 24 hours (S.D. \pm 26 ) and for hypertensives $90 \mu \mathrm{g}$. per 24 hours (S.D. \pm 36$)$; there is clearly no difference between these groups.

Holtz, Credner, and Kroneberg (1947) obtained values of 100 to $150 \mu \mathrm{g}$. of adrenaline or noradrenaline per day and stated that some subjects with essential hypertension excreted larger amounts. In a series examined by Burn (1953) bio-assay gave 15-150 $\mu \mathrm{g}$. for normotensive adults with a mean value of $75 \mu \mathrm{g}$; hypertensives did not give higher figures. Von Euler and Hellner (1951), also by bio-assay, found the total catecholamine excretion in healthy students to be 19-69 $\mu \mathrm{g}$. per day. In a group of hypertensives von Euler (1952) found $66 \%$ to excrete less than $58 \mu \mathrm{g}$. noradrenaline in 24 hours and $32 \%$ up to $200 \mu \mathrm{g}$., while Goldenberg et al. (1954) report values obtained by bio-assay of 11 to $50 \mu \mathrm{g}$. per day for normals and up to $100 \mu \mathrm{g}$. for essential hypertensives. These results, suggesting that hyper-

TABLE III

TOTAL CATECHOLAMINE EXCRETION AS NORADRENALINE ( $\mu \mathrm{G} .24$ HOURS) IN NORMAL AND HYPERTENSIVE SUBJECTS

\begin{tabular}{|c|c|c|c|c|c|c|c|}
\hline \multicolumn{4}{|c|}{ Normal } & \multicolumn{4}{|c|}{ Hypertensive } \\
\hline Sex & Age & $\begin{array}{c}\text { Blood } \\
\text { Pressure } \\
(\mathrm{mm} . \mathrm{Hg})\end{array}$ & $\begin{array}{l}\text { Catechol- } \\
\text { amines }\end{array}$ & Sex & Age & $\begin{array}{c}\text { Blood } \\
\text { Pressure } \\
(\mathrm{mm} . \mathrm{Hg})\end{array}$ & $\begin{array}{l}\text { Catechol- } \\
\text { amines }\end{array}$ \\
\hline $\begin{array}{l}\mathbf{F} \\
\mathbf{F} \\
\mathbf{F} \\
\mathbf{M} \\
\mathbf{M} \\
\mathbf{M} \\
\mathbf{M} \\
\mathbf{M} \\
\mathbf{M} \\
\mathbf{F} \\
\mathbf{M} \\
\mathbf{M}\end{array}$ & $\begin{array}{l}22 \\
27 \\
48 \\
59 \\
50 \\
53 \\
55 \\
52 \\
55 \\
30 \\
44 \\
52\end{array}$ & $\begin{array}{l}110 / 70 \\
110 / 75 \\
120 / 75 \\
120 / 80 \\
130 / 75 \\
130 / 75 \\
130 / 80 \\
135 / 80 \\
135 / 80 \\
135 / 80 \\
135 / 90 \\
135 / 80\end{array}$ & $\begin{array}{r}135 \\
33 \\
100 \\
94 \\
92 \\
94 \\
105 \\
92 \\
57 \\
87 \\
93 \\
85\end{array}$ & $\begin{array}{l}\mathbf{M} \\
\mathbf{F} \\
\mathbf{F} \\
\mathbf{F} \\
\mathbf{F} \\
\mathbf{F} \\
\mathbf{M} \\
\mathbf{F} \\
\mathbf{M} \\
\mathbf{M} \\
\mathbf{M} \\
\mathbf{M} \\
\mathbf{M} \\
\mathbf{M} \\
\mathbf{M} \\
\mathbf{F}\end{array}$ & $\begin{array}{l}81 \\
61 \\
54 \\
44 \\
71 \\
45 \\
33 \\
65 \\
64 \\
45 \\
56 \\
58 \\
49 \\
54 \\
43 \\
68\end{array}$ & 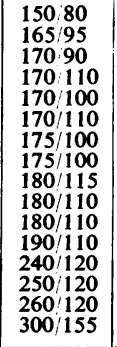 & $\begin{array}{r}119 \\
54 \\
121 \\
77 \\
45 \\
63 \\
90 \\
63 \\
135 \\
69 \\
130 \\
135 \\
149 \\
87 \\
60 \\
45\end{array}$ \\
\hline \multirow[t]{2}{*}{ Mean } & 45 & & 89 & & 56 & & 90 \\
\hline & & & S.D. \pm 26 & & & & S.D. \pm 36 \\
\hline
\end{tabular}


tensive subjects excrete larger amounts of catecholamines than normals, are not confirmed by the results of Burn (1953) and those recorded in Table III.

We have had an opportunity to examine one case only of phaeochromocytoma while this work was in progress. Fluorimetric estimation of the total catecholamines as noradrenaline showed an excretion of $2,600 \mu \mathrm{g}$. in 24 hours.

\section{Discussion}

Extraction of catecholamines from urine by adsorption on aluminium hydroxide, as first described by Shaw (1938) and modified by von Euler (1948), is still the most satisfactory method. In our hands precipitation of the aluminium hydroxide in situ has yielded more consistent results than adsorption on a column of alumina (Lund, 1949 ; von Euler and Orwén, 1955). It is necessary, however, to work with a large volume of urine, otherwise high local concentration of alkali during the neutralization process is liable to destroy a high proportion of the catecholamines present.

Since, with the method described in this paper, adrenaline gives readings some $30 \%$ higher than corresponding amounts of noradrenaline our figures are liable to be too high in proportion to the amount of adrenaline present in the extracts. In the case of normal urines the adrenaline fraction of the catecholamines amounts to not more than $16 \%$ of the total (von Euler, HellnerBjörkman and Orwén, 1955) and serious errors are unlikely. In some cases of phaeochromocytoma the proportions of adrenaline are much greater, some $50-60 \%$, but, for clinical purposes, combined estimation of catecholamines as noradrenaline has no disadvantage.

Regarding the specificity of the fluorimetric method, according to Lund (1949) at least one hydrogen atom must be attached to the $\alpha$ - and $\beta$ carbon atoms of the side chain for the formation of fluorescent oxidation products. Of substances satisfying this condition adrenaline, noradrenaline, and DOPA (3:4-dihydroxyphenylalanine) alone are likely to be found in biological materials. Adrenaline and noradrenaline, $R_{F}$ values 0.36 and 0.28 respectively, occur closely together, while DOPA, $R_{F}$ value 0.19 , would not be included by the method described. The presence of DOPA in phaeochromocytomata has recently been reported by Weil-Malherbe (1956), but it has not been detected in the urine. The other substance excreted in increased amounts in phaeo- chromocytoma, 3-hydroxytyramine, $R_{F}$ value 0.39 , does not give a fluorescent compound on oxidation with ferricyanide. We may conclude, therefore, that the specificity of the method for adrenaline and noradrenaline is of a high degree.

\section{Summary}

A fluorimetric method for the clinical estimation of the total combined adrenaline and noradrenaline in urine, based on the ferricyanide oxidation method of von Euler, is described.

The standard error of a single determination was $\pm 1.9 \mu \mathrm{g}$. per $500 \mathrm{ml}$. urine on amounts of 15 to $40 \mu \mathrm{g}$. Recovery of noradrenaline added to urine was $92 \%$, S.D. \pm 9 .

Comparison of results obtained by bio-assay with those of fluorimetry showed no significant difference.

Values are given for the total excretion of adrenaline and noradrenaline in a series of normal and hypertensive subjects ; there was no difference between the two groups, the range of excretion being 30-150 $\mu$ g. per day.

We are most grateful to Dr. R. S. Stacey for facilities and for help given to one of us (W. J. G.) in the performance of the bio-assays. Our thanks are due to Messrs. Bayer Products, Ltd., for a generous gift of L-noradrenaline.

\section{Addendum}

Since writing this paper the number of normal subjects examined has been brought to 25 . For the entire group the daily excretion of catecholamines as noradrenaline ranged from 25 to 150 $\mu$ g., mean $82 \mu$ g. (S.D. \pm 29 ).

Seventy-five hypertensive subjects, in the majority of whom a phaeochromocytoma was suspected, have been examined. In four only was the excretion of catecholamines as noradrenaline $>150 \mu \mathrm{g}$. per 24 hours. Of these, one, $\stackrel{\sim}{\circ}$ who excreted 1,240 $\mu \mathrm{g}$., had had a phaeochromo- $N$ cytoma removed and was known to have another; N in the second, excreting $2,600 \mu \mathrm{g}$., a tumour was found and removed, while in a third patient, whose catecholamine excretion was 185 to $270 \stackrel{0}{\circ}$ $\mu \mathrm{g}$., bilateral exploration of the adrenals was un- $\stackrel{\mathcal{\Phi}}{\rightarrow}$ successful. The fourth patient, exhibiting values of 110 to $195 \mu \mathrm{g}$., was not surgically explored.

Phaeochromocytomata associated with nor- $\overrightarrow{\mathbb{D}}$ adrenaline excretions of 180 to $300 \mu \mathrm{g}$. per $24 \stackrel{\Phi}{\Phi}$ hours have been reported by Engel and Euler $\frac{\varrho}{\sigma}$ (1950), Lund (1952), Burn (1953), and Goldenberg et al. (1954). 


\section{REFERENCES}

Burn, G. P. (1953). Brit. med. J., 1, 697.

Engel, A., and Euler, U. S. von (1950). Lancet, 2, 387.

Euler, U. S. von (1948). Arch. int. Pharmacodyn., 77, 477.

- (1952). Scand. J. clin. Lab. Invest., 4, 254.

and Floding, I. (1955a). Acta physiol. scand., Suppl. 118, p. 45.

(1955b). Ibid., Suppl. 118, p. 57.

and Hellner, S. (1951). Ibid., 22, 161.

Hellner-Björkman, S., and Orwén, I. (1955). Ibid., Suppl. 118, p. 10.

- and Orwén, I. (1955). Ibid., Suppl. 118, p. 1.

Goldenberg, M., Serlin, I., Edwards, T., and Rapport, M. M. (1954). Amer. J. Med., 16, 310.
Holton, Pamela (1949). Nature (Lond.), 163, 217.

Holtz, P., Credner, K., and Kroneberg, G. (1947). Arch. exp. Path. Pharmak., 204, 228.

Lund, A. (1949). Acta pharmacol. (Kbh.), 5, 231.

- (1950). Ibid., 6, 137.

(1952). Scand. J. clin. Lab. Invest., 4, 263.

Shaw, F. H. (1938). Biochem. J., 32, 19.

Shepherd, D. M., and West, G. B. (1953). Nature (Lond.), 171, 1160.

Weil-Malherbe, H. (1956). Lancet, 2, 282.

- and Bone, A. D. (1952). Biochem. J., 51, 311.

- (1953). Lancet, 1, 974.

- (1954). Biochem. J., 58. 132 